\title{
Visual skills and playing positions of Olympic hockey
}

\section{players}

\section{Z. L. WIMSHURST}

University of Surrey

British Olympic Medical Institute, London

University College London, Division of Surgical and Interventional Medicine

P. T. SOWDEN

University of Surrey

M. CARDINALE

British Olympic Medical Institute, London

University College London, Division of Surgical and Interventional Medicine

University of Aberdeen, School of Medical Science,

Address correspondence to: Zöe L. Wimshurst,

Department of Psychology, University of Surrey, Guildford, Surrey GU2 7XH or e-mail (Z.Wimshurst@surrey.ac.uk)

Tel: +44(0)1483 689446

Running title: Visual skills of Olympic hockey players

Keywords: Vision, visual abilities, hockey, vision screening 
Summary - Many sports require fine spatiotemporal resolution for optimal performance. Previous studies have compared anticipatory skills and the decision making process in athletes; however, information is lacking on visual skills of elite athletes. To assess visual skills of Olympic hockey players and analyse differences by playing position and to analyse improvement of visual skills after training, 21 Olympic hockey players were pre- and posttested on 11 visual tasks following a 10-week visual training programme. The lack of mean differences at pre-test between players of different positions suggested visual skills are independent of playing position; however, after training, an improvement was seen in all players with goalkeepers improving significantly more than outfield players. 


\section{Introduction}

In any position of any sport, vision provides the athlete with information regarding

where, when and what to do. Regardless of physical strength, speed, and technical skill of an individual, ability to quickly and correctly process visual information presented to them can differentiate between elite and non elite performers. This was summed up succinctly by the legendary American Football coach, Blanton Collier (1979) who developed the concept that 'the eyes lead the body'. It is estimated that $85-90 \%$ of sensory information regarding the external environment is obtained visually (Loran \& MacEwen, 1995). Considering the speed at which ball games are played nowadays, it seems feasible to state that visual processing in a sport setting is one of the most demanding activities faced by the human visual system. Previous studies have identified marked differences between elite and nonelite sport performers in a variety of visual skills including dynamic visual acuity (Barnes \& Schmid, 2002; Millslagle, 2000), stereopsis (Coffey \& Reichow, 1990), saccades (Christenson \& Winkelstein, 1988; Zhang \& Watanabe, 2005), pursuit (Bahill \& LaRitz, 1984), hand-eye coordination (Vogel \& Hale, 1992), visual reaction time (Dogan, 2009), peripheral awareness (Zweirko, 2008), speed of recognition (Isaacs \& Finch, 1983) attentional processing (Overney, Blanke \& Herzog, 2008), and visual field (Berg \& Killian, 1995). In team ball sports each position has very different physical, tactical and skill related demands. As with the differences highlighted between elite and nonelite athletes, it could be argued that different positions in ball games might demand different visual skills. It has been shown that various sports require different visual abilities (Dogan, 2009), and it makes sense that visual demands which are position-dependent will vary across players, in particular, in sports where goalkeepers often carry out a very specific role within a team. In field hockey, goalkeepers have to face powerful shots coming towards them at different angles, heights and speeds. 
1 Defenders need to be able to watch the player they are marking as well as tracking the ball

2 which could be some distance away. Midfielders should constantly be aware of what is

3 happening around them to select the correct pass and make interceptions, and forwards need

4 to use their skills to avoid a defender's tackle and spot spaces into which they can move.

5 Given the diverse visual tasks to which hockey players are exposed and with further

6 differences experienced when playing positions are taken into consideration, it could be

7 hypothesised that visual demands between positions would differ. In particular, given

8 empirical observations from the coaching community, it would seem that goalkeepers should

9 score better than other players. However, despite the need for understanding visual skills in

10 hockey not only as talent identification but also in performance, few researchers have tried to

11 define visual skills of elite players and understand any differences by playing position.

Bhanot \& Sidhu (1980) assessed the visual reaction time of 92 hockey players and found

defenders had the fastest reaction times and midfielders the slowest. Calder (1999) examined a wide range of visual skills (including peripheral vision, visual reaction time, visual acuity, visual memory, eye movement skills, visual concentration, visual recognition and balance) of elite hockey players and found no significant differences across playing positions. No other study was found in which visual skills of elite hockey players were analysed to assess differences by playing position.

While evidence suggests different visual skills for athletes of varying qualification, there is no information on positional differences although such differences are marked in terms of movement patterns. MacLeod, Bussell \& Sunderland (2007) examined motion frequency of elite female hockey players and found that defenders spent less time walking, but a greater amount of time in activity of low intensity than forwards and midfielders. Similar positional differences in movement and activity patterns have been observed in other sports including rugby union, football and cricket (Deutsch, Kearney \& Rehrer, 2007; Reilly 
1 and Thomas, 1976; Petersen, Pyne, Portus \& Dawson, 2009). Sports vision-training

2 programmes have been suggested to athletes to improve performance. Although in certain

3

4 cases it has been seen that specific vision training has not shown improvements in visual acuity and peripheral acuity (Westheimer, 2001; Abernethy \& Wood, 2001), vision function and shooting skills were enhanced in Olympic shooters who participated in an unspecified vision training programme lasting approximately 20 hours over a 3-month period (Quevedo \& Sole, 1995). Furthermore, West and Bressan (1996) showed improvements in visual skills of cricket players with a vision training programme involving seven skills. Similar improvements have been reported for college basketball players (Kofsky \& Starfield, 1989) and varsity soccer players (McLeod, 1991). It is possible that, if a large number of repetitions were used to coach a particular visual skill, a significant improvement in visual performance could be obtained (For review see Ciuffreda \& Wang, 2004, and Williams \& Grant, 1999). Athletes are assigned to specific playing positions during the course of their athletic development given a variety of abilities and anthropometric characteristics. Limited information is available on their visual skills and notably is lacking on the trainability of such skills by playing position. The primary aim of this work was therefore to provide a comprehensive assessment of visual skills of elite hockey players and to analyse the differences between playing positions. A secondary aim was to verify the effectiveness of a vision training programme with particular reference to differences in playing positions.

Method

Participants

Twenty-one male international hockey players (mean age 25.4, SD = 5 years) participated in a sports vision-training programme. All were members of the Olympic team. Participants were split into groups depending on their playing position for the national team 
1 (Goalkeepers, = 3; Defenders, =6; Midfielders, =6; Forwards, =6). All participants gave

2 informed consent, and all procedures complied with the University of Surrey ethical

3 guidelines.

4

$5 \quad$ Testing Task

6 The six computer-based visual tasks are described as follows:

Dynamic Shape Recognition involved watching a row of arrows move rapidly across the

8 screen and pressing the cursor key (with their preferred finger on their dominant hand) matching the direction that each arrow was pointing. For example, the arrows were scrolling from left to right across the screen, and the participant had to respond starting with the uppermost arrow and work downward (see Figure 1a). In this case, the correct sequence was to press the right-pointing cursor key, then the right again, then down, two more right, down twice, left, etc. Following each key press, the arrow being responded to disappeared.

\section{$<$ FIGURE 1 ABOUT HERE $>$}

Rotational Acuity involved watching a series of Landolt Cs rotate in rings around a central point and detecting where the opening in each was. Adjacent rings rotated in opposite directions. For example, there were four rings each made up of five or six Landolt Cs (see Figure 1b). Participants responded from the inner most ring first, starting with a green coloured circle. The task was to press the arrow key corresponding to the position of the opening in the Landolt C. For this example the correct responses for the first ring were right, right, down, right, left, up.

Saccadic Eye Movements were measured when a Landolt C appeared at a random location on the screen and disappeared after $250 \mathrm{~m} / \mathrm{sec}$. Participants had to move their eyes quickly to the $\mathrm{C}$ and recognise where the opening was. Immediately following the response, another $\mathrm{C}$ appeared elsewhere on screen. In the example shown in Figure 1c, a participant 
1 had to press the right arrow key and then another $\mathrm{C}$ would appear. This tests saccadic eye

2 movements as participants had to move their eyes very quickly between locations and focus

3 on the Landolt $\mathrm{C}$ to detect where the opening lay in each.

For Peripheral Awareness nine shapes, arranged in a 3x3 square, appeared on the screen

5 for $200 \mathrm{~m} / \mathrm{sec}$. The shape in the centre of the grid matched one of those surrounding it, and

6 participants had to locate the matching shape by using the number pad on the side of the

7 keyboard. In the example shown in Figure 1d, the correct response was to press the number 9

8 key on the grid as the matching shape was in the top right hand corner. The correct answer

9 for Figure 1e was the number 8 key as the matching shape was in the top middle position.

10 The short stimulus duration ensured that participants had to focus on the central shape and

11 use their peripheral vision to detect which of the surrounding shapes matched. The size of the grid varied so peripheral awareness at different visual eccentricities was trained. The overall display size was $25^{\circ} \times 16^{\circ}$ and the furthest symbol was $13^{\circ}$ from fixation placing it in the visual periphery.

Focus Acuity was measured in a similar way to rotational skills but with the Landolt Cs rotating in an orbital path rather than in two-dimensional rings (see Figure 1f). Participants started with the innermost ring and again responded using the arrow keys to show where they thought the opening in the Landolt C appeared. Because the Landolt Cs appeared to move from near to far the participants’ eyes had to track them through various apparent depths.

For Dynamic Visual Acuity, a chain of Landolt Cs moved around the screen in a snakelike manner (see Figure 1g). Participants had to detect the opening of each $\mathrm{C}$ as these moved around, starting with the 'leading' end of the snake. This task forced participants to keep the Landolt Cs in focus so that the opening could be detected, whilst the Cs were moving around unpredictably. 
1 Each of these tasks had 30 levels with increasing difficulty (difficulty increase by

2 variously by increasing the speed at which a target moved, reducing the time a target was

visible for, changing the background to make the target less obvious); the testing was carried

4

out on Level 21 (out of 30 - with Level 1 being the easiest level and 30 being the most

difficult). Each level had ten repetitions to make the complete test. In order to progress to the next level an athlete had to score $90 \%$ or over the ten repetitions. Score was calculated by number of correct responses in the allocated time. Athletes had a maximum of 20 second to complete each individual repetition and then there was a five second break before the next repetition began.

The five practical tasks are described now and in the order in which they were administered:

For Horizontal Saccades (HORSAC) two 10x10 Snellen letter-acuity charts were placed side-by-side one metre apart at eye level on the wall. Participants stood one arm's distance from the wall, lined up centrally between the charts and, keeping the head as still as possible, read letters alternately from each chart. The score was the number of correct letters read in one minute.

Vertical Saccades was the same as Horizontal Saccades but with the letter charts placed vertically one above the other rather than side-by-side.

For Focus Flexibility participants stood three metres from a 10x10 letter chart displayed at eye-level. They held in their hands another 10x10 chart and read alternate letters from the near and far charts. The score was the number of letters correctly read in one minute.

The Rotator Board test required a circular board with a diameter of $30 \mathrm{~cm}$ to be spun on a turntable at a speed of $2 \mathrm{sec} . /$ rotation. The board had each letter of the alphabet randomly printed on it with a hole alongside (see Figure 1h). Participants had one minute to place a 
1 golf-tee in the hole beside each letter in alphabetical order. The score was the number of

2 letters each successfully completed within the minute.

3

4

5

6

During the Recognition Task participants watched a number of short film clips, and after each clip answered a question related to what they had seen. Questions were designed to assess several different areas of visual activity, including eye movements, speed of focusing, depth perception, fixation ability, colour perception, and visual memory. For example, participants were asked questions such as how many characters they could count, what appeared on a wall, and which of two characters was farther away.

\section{Testing Protocols}

Participants performed the tests in two testing sessions separated by $24 \mathrm{~h}$ but in the first testing session participants performed the computer tasks; in the second one they performed the practical tasks.

\section{Training Programme}

The players took part in a ten-week training programme during the build-up to their qualification for, and participation in, the Beijing 2008 Olympic Games. The training programme consisted of six computer-based exercises which the players practised three times per week for 20 minutes per session and four practical exercises which were practised for one hour per week.

The computer-based training was provided on the six previously described exercises. The players began on Level 1 and once they achieved over a 90\% success rate, they could progress to the next level. Each level became more difficult through a combination of shorter time limit, shapes/Landolt Cs appearing for a shorter period of time, and items moving around the screen more quickly. The four practical exercises for which training was given 
1 were the Horizontal Saccades, Vertical Saccades, Focus Flexibility, and Rotator Board.

2 Different stimuli were used for training and testing. Testing was repeated at the end of the training programme with the same protocols except for the Recognition task. No specific training was given for this task, and there were two separate sets of clips, half the participants saw Set 1 at pre-test and Set 2 at post-test; the other participants saw Set 2 at pre-test and Set 1 at post-test.

\section{Statistical Analysis}

All data are presented as mean \pm standard error of measurement. Comparisons between athletes grouped by playing positions were performed using Anova with Tukey's post hoc tests. The correlations between scores on the visual skills tests were analysed using the Pearson product-moment correlation coefficient. A 3-way Anova with playing position as the between subjects variable and time (pre- or post-test) and task as the within subjects variable was used to analyse the effects of the training programme. Alpha was set at .05.



The Pearson product-moment correlations among tasks are was carried out and found a moderate to large relationship between scores on Horizontal Saccades with those on Vertical Saccades $(.75[<.05])$, but no other scores for these tasks were correlated. 
When comparing training data pre- and post-test, the three-way Anova showed a significant main effect for playing position, $\mathrm{F}(3,17)=3.124 ; \mathrm{P}<0.05$; partial $\eta^{2}=0.405$; observed power $=.72$. A post hoc Tukey HSD showed that goalkeepers performed significantly better than defenders $(\mathrm{P}<.05)$. This was the only significant finding although better performance by goalkeepers than forwards fell short of significance ( $\mathrm{P}=.09$, see Table 2). For means and SEs of raw scores at post-test see Table 2.

\section{$<$ TABLE 2 ABOUT HERE $>$}

The three-way Anova also showed a significant main effect for time, $F(1,17)=328.26$; $\mathrm{P}<0.001$, partial $\eta^{2}=0.951$, observed power $=1$. Pre- to post-test improvements can be seen in Figure 3.

\section{<FIGURE 3 ABOUT HERE>}

A significant interaction was found between playing position and time, $F(3,17)=6.16$; $\mathrm{P}<0.001$, partial $\eta^{2}=0.52$, observed power $=0.909$. Whilst outfield players improved by approximately the same amount from pre- to post-test, the goalkeepers improved by a larger margin (see Figure 4). Tukey tests confirm this by showing no significant differences between any groups at pre-test whereas at post-test goalkeepers were performing significantly better than defenders $(\mathrm{P}<.001)$ and forwards $(\mathrm{P}<.05)$. Tukey post hoc tests also show that all groups significantly improved over the course of the training programme $(\mathrm{P}<.001)$.

\section{$<$ FIGURE 4 ABOUT HERE $>$}

There was no significant interaction between task and position; $F(3,17)=0.58 ; p=0.95$, partial $\eta^{2}=0.09$, observed power $=0.534$ however, there was a significant interaction between time and task, $\mathrm{F}(1,17)=2.32 ; \mathrm{p}<.05$, partial $\eta^{2}=0.12$, observed power $=0.92$. Tukey post hoc testing showed that performance on all tasks was significantly better at posttest when compared to pre-test $(\mathrm{p}<.001)$ with the exception of Focus Acuity, where there was no significant difference $(\mathrm{p}=.28)$. Also, the three-way interaction was significant among 
1 time, task, and position $\mathrm{F}(3,17)=1.85$; $\mathrm{p}<0.01$, partial $\eta^{2}=0.246$, observed power $=0.994$.

2 This interaction effect shows that improvement varied by position as well as task. Figure 5

3 shows the percent improvements for each position separately for the each task.

\section{<FIGURE 5 ABOUT HERE>}

\section{Discussion}

The initial data comparing results by position is supportive of the previous work by Calder (1999) in showing no statistically significant differences between players’ positions across the range of visual skill tasks. This finding, together with the numerous studies in which expert athletes demonstrate superior visual skills to novice athletes (e.g., dynamic visual acuity by Barnes \& Schmid, 2002; saccadic eye movements by Christenson \& Winkelstein, 1988; stereopsis by Coffey \& Reichow, 1990; peripheral awareness by Zweirko; 2008), is consistent with the possibilities that either to reach this elite level of play athletes have superior innate visual skills or that playing sport at a high level increases visual skills of all individuals. It is the faster, more demanding pace of the game that requires players show such increases rather than differences in the specific visual demands faced by individuals in a playing position.

Unlike previous studies, in which positional differences have been examined only without visual training, retesting the same participants was included here and scores by position after a 10 -week visual training programme showed significant improvements across all participants from pre-test to post-test. One may conclude participation in the visual training programme increased visual skills of these elite hockey players. More interestingly, goalkeepers outperformed all other groups at the post-test (significantly better than defenders). As there were no differences among positions at the pre-test, goalkeepers responded better to the visual training programme than any of the outfield players. A look at 
1 scores on the individual tasks shows that goalkeepers significantly outperformed all other

2 positions on Horizontal Saccades, Vertical Saccades, and Focus Flexibility after the vision

3 training. These three tests involve moving the eyes swiftly from one place to another and then

4 focusing quickly. These visual skills are similar to those goalkeepers employ for much of the

5 hockey match when they are watching the ball being moved around the pitch. Considering all

6 players had the same exposure to hockey-specific training, it is likely that the observed

7 changes are due to the vision-specific training performed.

Within the limitations of this study design it is difficult to explain why goalkeepers

improved the most on specific tasks. However, in a team sport such as hockey, the position of goalkeeper is relatively separate from those of the rest of the team. The goalkeepers require a vastly different skill set and they spend more time alone (or just with the other goalkeeper on the team) during training and match preparation. This may mean, while the overall training time is exactly the same as that of their field teammates, they get exposed to more high speed tasks in some training time dedicated to goalkeeping skills. Nevertheless, if the differences are due to hockey-related training it does not explain why there were no differences at pretest as all players had been undergoing similar training regimes for several years. It is possible that the goalkeepers were differently motivated than the outfield players to put more effort into the visual training tasks. Whilst all hockey players require excellent visual skills in order to be able to perform to their optimum, a breakdown in visual skills by a goalkeeper is likely to result in conceding a goal, whereas if an outfield player has a breakdown in visual skills it may just mean then do not select the best possible pass and thus is easier to mask. Further, the three goalkeepers used in this study were competing for just one place on the Olympic team, whereas the eighteen field players were competing for one of fifteen places so there would have been greater levels of direct competition between the goalkeepers and thus their motivation to succeed in every area may have been greater. 
To conclude, prior to any visual training there were no differences in visual skills

2 across players of different positions within an elite hockey team. However, after a 10-week

3 visual training programme goalkeepers were significantly outperforming outfield players on a

$4 \quad$ number of visual tasks while all players showed benefit. Further studies are needed using

5 randomised cross-over designs for longer periods of time to evaluate the extent of

6 effectiveness of specific visual training programmes on various visual skills in elite

7 populations. It is also important to find ways to quantify on-pitch performance and to monitor

8 this over the course of a visual training programme to assess association between

9 improvement in visual skill and sport-specific performance. These preliminary data suggest

10 the possibility of improving visual skills even in an elite population. 
2 Abernethy, B., \& Wood, J. M. (2001) Do generalized visual training programmes for sport really work? An experimental investigation. Journal of Sports Sciences, 19, 203-222.

Bahill, A. T., \& LaRitz, T. (1984) Why can’t batters keep their eyes on the ball? American Scientist, 73, 249-253.

6 Barnes, G. R., \& Schmid, A. M. (2002) Sequence learning in human ocular smooth pursuit. Experimental Brain Research, 144, 322-355.

Berg, W. P., \& Killian, S. M. (1995) Size of the visual field in collegiate fast-pitch softball players and nonathletes. Perceptual and Motor Skills, 81, 1307-1312.

Bhanot, J. L., \& Sidhu, L. S. (1980) Reaction time of hockey players with reference to their field positions. Journal of Sports Medicine, 20, 423-430.

Collier, B. (1979) The eyes lead the body. Optometry Management, 15, 73. 
professional rugby union players during match-play. Journal of Sports Sciences, 25, $461-472$.

Dogan, B. (2009) Multiple-choice reaction and visual perception in female and male elite athletes. Journal of Sports Medicine and Physical Fitness, 49, 91-96.

Isaacs, L.D. \& Finch, A.E. (1983) Anticipatory timing of beginning and intermediate tennis players. Perceptual and motor skills. 57, 451-454.

Kofsky, M., \& Starfield, B. (1989) Sports vision visual training and experimental program with Australian Institute of Sport basketball players. Australian Journal of Optometry, $6,15-17$.

Loran, D. F. C., \& MacEwen, C. J. (1995) Sports Vision. Oxford: Butterworth-Heinemann.

MacLeod, H., Bussell, C., \& Sunderland, C. (2007) Time-motion analysis of elite women’s field hockey, with particular preference to maximum intensity movement patterns. International Journal of Performance Analysis in Sport, 7, 1-12.

McLeod, B. (1991) Effects of eyerobics visual skills training on selected performance measures of female varsity soccer players. Perceptual and Motor Skills, 72, 863-866.

Millslagle, D. G. (2000) Dynamic visual acuity and coincidence-anticipation timing by experienced and inexperienced women players of fast pitch softball. Perceptual and Motor Skills, 90, 498-504.

Overney, L. S., Blanke, O., \& Herzog, M. H. (2008) Enhanced temporal but not attentional processing in expert tennis players. PLoS One, 3, 2380.

Petersen, C., Pyne, D., Portus, M., \& Dawson, B. (2009) Validity and reliability of GPS units to monitor cricket-specific movement patterns. International Journal of Sports Physiology and Performance, 4, 381-393.

Quevedo, L., \& Sole, J. (1995) Visual training programme applied to precision shooting. Ophthalmic and Physiological Optics, 15, 519-523. 
1 Reilly, T., \& Thomas, V. (1976) Motion analysis of work-rate in different positional roles in

2 professional football match-play. Journal of Human Movement Studies, 2, 87-97.

Vogel, G. L. \& Hale, R. E. (1992) Does participation in organised athletics increase a child’s scoring ability on the Wayne Saccadic Fixator? Journal of Behavioural Optometry, 3, 66-69.

West, K. L., \& Bressan, E. S. (1996) The effect of a general versus specific visual skills training programme on accuracy in judging length-of-ball in cricket. International Journal of Sports Vision, 3, 41-45.

Westheimer, G. (2001) Is peripheral visual acuity susceptible to perceptual learning in the adult? Vision Research, 41, 47-52.

Williams, A. M., \& Grant, A. (1999) Training perceptual skill in sport. International Journal of Sport Psychology, 30, 194-220.

Zhang, J., \& Watanabe, K. (2005) Differences in saccadic latency and express saccades between skills and novice ball players in tracking predictable and unpredictable targets and two visual angles. Perceptual and Motor Skills, 100, 1127-1136.

Zwierko, T. (2008) Differences in peripheral perception between athletes and nonathletes. Journal of Human Kinetics, 19, 53-62. 
Figure 1. Screenshots of each of the computer based training tasks and of one practical task. a) Dynamic Shape Recognition - participants identify the direction that each arrow points as they move across the screen.

b) Rotational Acuity - participants identify the opening in each Landolt C starting with the inner ring. The arrow indicate that the Cs rotated. Alternating rings rotating in opposite directions.

c) Saccadic Eye Movements - participants identified the opening in a Landolt C presented for $250 \mathrm{~m} / \mathrm{sec}$ at a random screen location.

d) and e) Peripheral Awareness - participants identified which outer shape matched the one in the centre at various eccentricities.

f) Focus Acuity - participants identify the opening in each Landolt $C$ starting with the inner ring. The arrow indicates that the Cs rotated in apparent depth. Alternating rings rotated in opposite directions.

g) Dynamic Visual Acuity - participants track a chain of Landolt Cs moving around the screen and identify the opening in each. h) Rotator Board - participants place a peg in the hole next to each letter of the alphabet in sequence.

Table 1

Raw Scores for All Participants by Task Pre-test and Post-test Mean and Standard Error

Pre-test

Post-test

Percentage improvement

\begin{tabular}{lccccc}
\hline Task & Mean & SE & Mean & SE & \\
\hline $\begin{array}{l}\text { Dynamic Shape } \\
\text { Recognition }\end{array}$ & 56.6 & 2.1 & 70.9 & 1.8 & 25.3 \\
\hline Rotation Acuity & 30.2 & 1.9 & 42.6 & 1.6 & 41.1 \\
\hline $\begin{array}{l}\text { Saccadic Eye } \\
\text { Movements }\end{array}$ & 48.1 & 2.4 & 64.3 & 2.9 & 33.7 \\
\hline $\begin{array}{l}\text { Peripheral } \\
\text { Awareness }\end{array}$ & 37.0 & 2.8 & 44.1 & 3.1 & 19.2 \\
\hline Focus Acuity & 35.4 & 2.1 & 54.2 & 2.7 & 53.1 \\
\hline $\begin{array}{l}\text { Dynamic Visual } \\
\text { Acuity }\end{array}$ & 73.6 & 3.0 & 87.2 & 1.4 & 18.5 \\
\hline $\begin{array}{l}\text { Horizontal } \\
\text { Saccades }\end{array}$ & 64.6 & 2.1 & 86.2 & 2.8 & 33.4 \\
\hline $\begin{array}{l}\text { Vertical } \\
\text { Saccades }\end{array}$ & 60.7 & 2.0 & 82.3 & 2.5 & 35.6 \\
\hline Focus Flexibility & 71.7 & 2.0 & 87.2 & 3.2 & 21.6 \\
\hline Rotator Board & 14.0 & 0.8 & 20.0 & 0.9 & 42.9 \\
\hline $\begin{array}{l}\text { Recognition } \\
\text { Task }\end{array}$ & 6.7 & 0.3 & 8.3 & 0.3 & 23.9 \\
\hline
\end{tabular}


Table 2

Raw Scores by Task and Playing Position at Pre-test and Post-test Mean and Standard Error

\begin{tabular}{|c|c|c|c|c|c|c|c|c|c|c|c|c|c|c|c|c|c|c|c|c|}
\hline \multirow{3}{*}{ Test } & \multicolumn{8}{|c|}{ Pre-test } & \multicolumn{8}{|c|}{ Post-test } & \multicolumn{4}{|c|}{ Percentage improvement } \\
\hline & \multicolumn{2}{|c|}{ GK } & \multicolumn{2}{|c|}{ Defender } & \multicolumn{2}{|c|}{ Midfield } & \multicolumn{2}{|c|}{ Forward } & \multicolumn{2}{|c|}{ GK } & \multicolumn{2}{|c|}{ Defender } & \multicolumn{2}{|c|}{ Midfield } & \multicolumn{2}{|c|}{ Forward } & \multirow{2}{*}{$\begin{array}{c}\text { GK } \\
\%\end{array}$} & \multirow{2}{*}{$\begin{array}{c}\text { Defender } \\
\%\end{array}$} & \multirow{2}{*}{$\begin{array}{c}\text { Midfield } \\
\%\end{array}$} & \multirow{2}{*}{$\frac{\text { Forward }}{\%}$} \\
\hline & $\mathbf{M}$ & SE & $\mathbf{M}$ & $\mathrm{SE}$ & $\mathbf{M}$ & SE & $\mathbf{M}$ & $\mathrm{SE}$ & $\mathbf{M}$ & SE & $\mathbf{M}$ & $\mathrm{SE}$ & $\mathbf{M}$ & SE & $\mathbf{M}$ & SE & & & & \\
\hline $\begin{array}{l}\text { Dynamic } \\
\text { Shape } \\
\text { Recognition }\end{array}$ & 57.0 & 2.4 & 53.6 & 5.0 & 56.6 & 4.2 & 59.3 & 4.1 & 75.5 & 2.0 & 66.4 & 3.2 & 72.3 & 2.9 & 71.5 & 4.6 & 32.5 & 23.9 & 27.7 & 20.6 \\
\hline $\begin{array}{l}\text { Rotation } \\
\text { Acuity }\end{array}$ & 40.7 & 8.8 & 28.3 & 3.6 & 29.5 & 3.0 & 27.6 & 1.7 & 48.3 & 2.0 & 40.9 & 1.3 & 43.3 & 2.6 & 40.8 & 4.7 & 18.7 & 44.5 & 46.8 & 47.8 \\
\hline $\begin{array}{l}\text { Saccadic } \\
\text { Eye } \\
\text { Movements }\end{array}$ & 51.5 & 10.0 & 42.7 & 3.5 & 54.2 & 3.8 & 48.6 & 4.2 & 76.5 & 4.8 & 61.5 & 5.2 & 65.3 & 4.6 & 60.1 & 6.7 & 48.5 & 44.0 & 20.5 & 23.7 \\
\hline $\begin{array}{l}\text { Peripheral } \\
\text { Awareness }\end{array}$ & 38.2 & 8.7 & 32.5 & 4.9 & 38.1 & 4.3 & 34.2 & 6.0 & 62.2 & 3.5 & 49.4 & 6.4 & 55.5 & 3.3 & 53.8 & 7.2 & 62.8 & 52.0 & 45.7 & 57.3 \\
\hline $\begin{array}{l}\text { Focus } \\
\text { Acuity }\end{array}$ & 42.0 & 3.9 & 31.7 & 5.6 & 41.7 & 2.5 & 35.0 & 4.4 & 53.3 & 2.0 & 36.3 & 3.1 & 48.7 & 3.6 & 42.7 & 7.9 & 26.9 & 14.5 & 16.8 & 22.0 \\
\hline $\begin{array}{l}\text { Dynamic } \\
\text { Visual } \\
\text { Acuity }\end{array}$ & 78.0 & 7.5 & 70.1 & 6.7 & 73.9 & 4.3 & 74.4 & 7.0 & 94.2 & 2.6 & 84.2 & 1.9 & 89.7 & 1.0 & 84.2 & 3.3 & 20.8 & 20.1 & 21.4 & 13.2 \\
\hline $\begin{array}{l}\text { Horizontal } \\
\text { Saccades }\end{array}$ & 62.0 & 10.8 & 63.3 & 3.8 & 67.2 & 4.4 & 64.5 & 2.4 & 108.3 & 6.6 & 79.3 & 4.2 & 86.5 & 4.2 & 81.8 & 1.2 & 74.8 & 25.3 & 28.7 & 26.8 \\
\hline $\begin{array}{l}\text { Vertical } \\
\text { Saccades }\end{array}$ & 56.7 & 8.3 & 59.0 & 2.5 & 65.3 & 3.3 & 58.3 & 4.3 & 104.7 & 4.8 & 73.7 & 1.8 & 82.2 & 3.4 & 80.0 & 2.3 & 84.7 & 24.9 & 25.9 & 37.2 \\
\hline $\begin{array}{l}\text { Focus } \\
\text { Flexibility }\end{array}$ & 77.3 & 6.0 & 66.5 & 3.5 & 77.0 & 2.1 & 66.7 & 3.9 & 113.3 & 9.7 & 80.5 & 4.0 & 83.2 & 3.5 & 85.0 & 4.3 & 46.6 & 21.1 & 8.1 & 27.4 \\
\hline $\begin{array}{l}\text { Rotator } \\
\text { Board }\end{array}$ & 15.3 & 1.9 & 13.3 & 1.5 & 14.0 & 1.5 & 14.2 & 1.5 & 18.7 & 3.2 & 18.8 & 1.1 & 22.0 & 1.6 & 19.7 & 2.2 & 22.2 & 41.4 & 57.1 & 38.7 \\
\hline $\begin{array}{l}\text { Recognition } \\
\text { Task }\end{array}$ & 5.7 & 0.9 & 6.8 & 0.3 & 6.5 & 0.7 & 7.3 & 0.3 & 9.7 & 0.3 & 7.3 & 0.7 & 8.0 & 0.5 & 8.8 & 0.6 & 70.2 & 7.4 & 23.1 & 20.5 \\
\hline
\end{tabular}




\section{$1 \quad$ Figure 1}
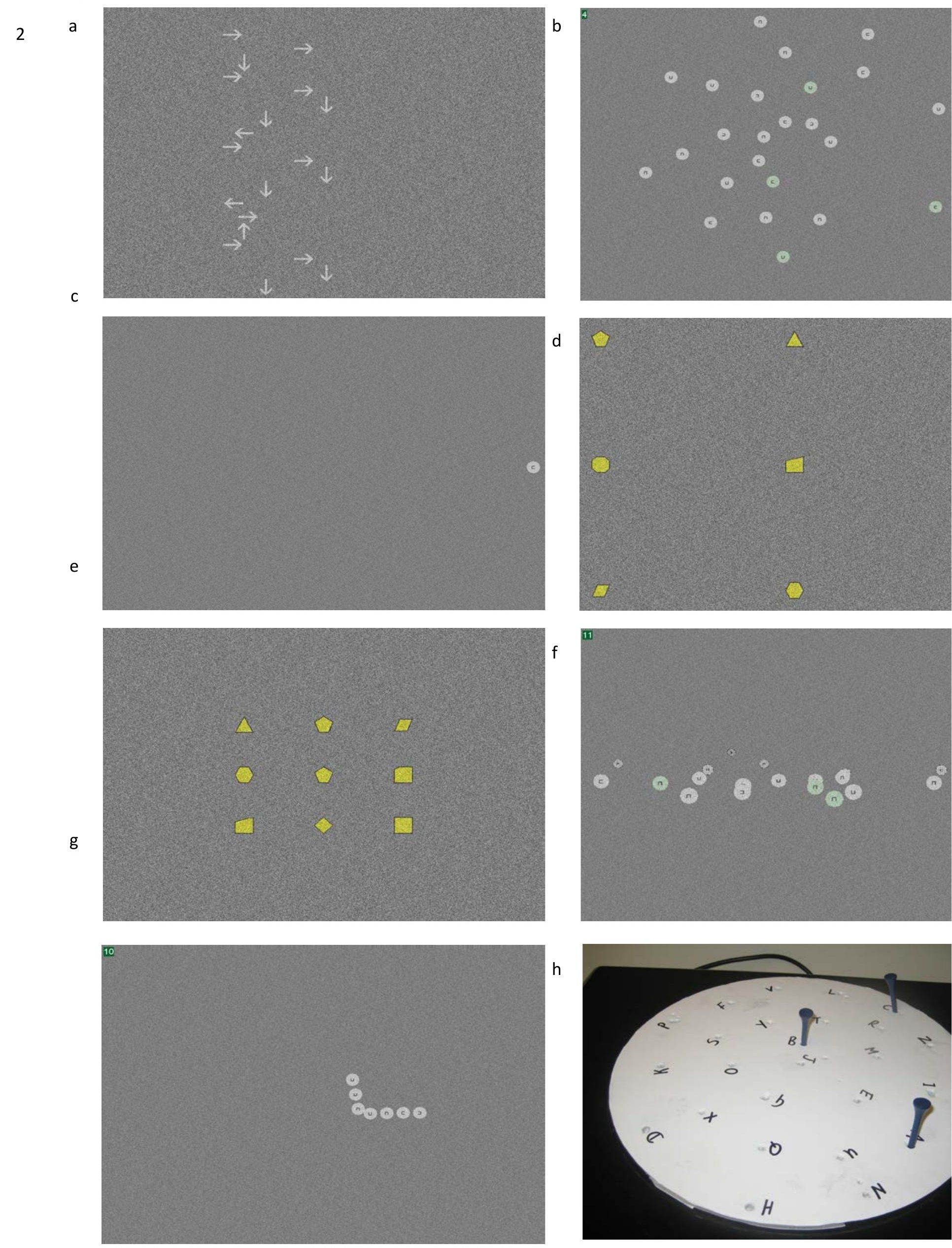